\title{
Hematopoietic stem cells promote the expansion and function of adoptively transferred antitumor $\mathrm{CD}^{+} \mathrm{T}$ cells
}

\author{
Claudia Wrzesinski, Chrystal M. Paulos, Luca Gattinoni, Douglas C. Palmer, \\ Andrew Kaiser, Zhiya Yu, Steven A. Rosenberg, and Nicholas P. Restifo
}

National Cancer Institute, NIH, Bethesda, Maryland, USA.

\begin{abstract}
Depleting host immune elements with nonmyeloablative regimens prior to the adoptive transfer of tumorspecific $\mathrm{CD8}^{+} \mathrm{T}$ cells significantly enhances tumor treatment. In the current study, superior antitumor efficacy was achieved by further increasing the intensity of lymphodepletion to a level that required HSC transplantation. Surprisingly, the HSC transplant and not the increased lymphodepletion caused a robust expansion of adoptively transferred tumor-specific $\mathrm{CD8}^{+} \mathrm{T}$ cells. The HSC-driven cell expansion of effector, but not of naive, $\mathrm{CD8}^{+} \mathrm{T}$ cells was independent of in vivo restimulation by MHC class I-expressing APCs. Simultaneously, HSCs also facilitated the reconstitution of the host lymphoid compartment, including inhibitory elements, not merely via the production of progeny cells but by enhancing the expansion of cells that had survived lymphodepletion. Profound lymphodepletion, by myeloablation or by genetic means, focused the nonspecific HSC boost preferentially toward the transferred tumor-specific $T$ cells, leading to successful tumor treatment. These findings indicate that $\mathrm{CD8}^{+} \mathrm{T}$ cell-mediated tumor responses can be efficiently driven by HSCs in the myeloablative setting and have substantial implications for the design of new antitumor immunotherapies.
\end{abstract}

\section{Introduction}

The adoptive cell transfer (ACT) of ex vivo activated autologous tumor-reactive $T$ cells is currently one of the most promising approaches for the treatment of patients with advanced melanoma (1-3). Immunization with therapeutic cancer vaccines can substantially increase the number of circulating tumor-reactive $\mathrm{CD}^{+}$CTLs and trigger tumor reduction in some cases, but neither the numbers nor the functions of these cells correlate with objective clinical responses (4). These findings may indicate that the $\mathrm{T}$ cells induced by vaccination are functionally tolerized. The growth of tumor-reactive $T$ cells ex vivo, unencumbered by the mechanisms that enforce functional tolerance in vivo, enables these self/tumor antigen-specific cells to become fully activated $(5,6)$. The ex vivo preparation of tumor-specific T cells for adoptive transfer also makes it possible to deplete host lymphocytes prior to the administration of antitumor T cells. Lymphodepletion prior to the transfer of tumor-reactive $\mathrm{CD}^{+} \mathrm{T}$ cells has been shown to enhance tumor destruction in mice (7-10). When these findings were translated to human trials, $51 \%$ of the patients experienced an objective response (11). In the setting of adoptive transfer for the treatment of solid tumors, the current lymphodepleting regimens are termed "nonmyeloablative" because they transiently deplete lymphocytes and do not lethally damage the host bone marrow and thus do not require $\operatorname{HSC}$ transfer $(9,12)$.

A lymphopenic environment can be induced by depleting endogenous immune cells via total body irradiation (TBI) or chemotherapy. The numbers of endogenous lymphocytes are tightly regulated by the host, and destruction of lymphocytes triggers the

Nonstandard abbreviations used: ACT, adoptive cell transfer; $\beta_{2} \mathrm{~m}, \beta_{2}$-microglobulin; MSC, myeloid suppressor cell; NT, no treatment; rhIL-2, recombinant human IL2; TBI, total body irradiation; TIL, tumor-infiltrating lymphocyte.

Conflict of interest: The authors have declared that no conflict of interest exists. Citation for this article: J. Clin. Invest. 117:492-501 (2007). doi:10.1172/JCI30414. homeostatic correction of the size of the lymphocyte compartment $(13,14)$. $\mathrm{CD}^{+} \mathrm{T}$ cells that are expanding into a lymphopenic environment acquire a memory-like phenotype and express high levels of CD44, Ly6C, and CD122 (15, 16). Lymphocyte activation after immunodepletion is also seen in the setting of adoptively transferred $T$ cells, where this activation is due, in part, to the increased availability of homeostatic cytokines that result from the removal of endogenous host cells acting as competitors for these cytokines (9). The specific homeostatic cytokines that play major roles include IL-7 and IL-15, cytokines that utilize the common $\gamma$ chain receptor $\left(\gamma_{C}\right)(14)$. Decreases in levels of host inhibitory elements, such as $\mathrm{CD} 4^{+} \mathrm{CD} 25^{+} \mathrm{Foxp} 3^{+}$Tregs, also facilitate the activation of adoptively transferred T cells $(17,18)$. Evidence for the increased activation of adoptively transferred $\mathrm{T}$ cells into immunodepleted hosts includes results of ex vivo analyses of IFN- $\gamma$ release and tumor cytolysis and in vivo measurement of tumor destruction $(9,15,16)$. The signal strength required to trigger proliferation and activation is considerably reduced, and low-affinity antigens such as self antigens and tumor antigens become sufficient triggering signals $(16,19,20)$.

Although ACT is a promising approach for the treatment of advanced melanoma patients, there is substantial opportunity for improvement $(1,21)$. Since nonmyeloablative lymphodepletion prior to ACT has been shown to improve tumor treatment outcome in mice and humans, we sought to explore whether we could significantly augment tumor destruction by increasing the intensity of lymphodepletion beyond the level currently used in ACT clinical trials. We employed the pmel-1 TCR-Tg mouse model wherein $\mathrm{CD}^{+} \mathrm{T}$ cells recognize the mouse gp100 tumor antigen, as this antigen is often a target in human clinical trials (6). As a tumor model, we treated established B16 tumors, which express the gp100 melanoma antigen. Prior to the adoptive transfer of pmel-1 CD8 ${ }^{+} \mathrm{T}$ cells, the intensity of the lymphodepletion used to precondition the host was increased to a level that required an 
A

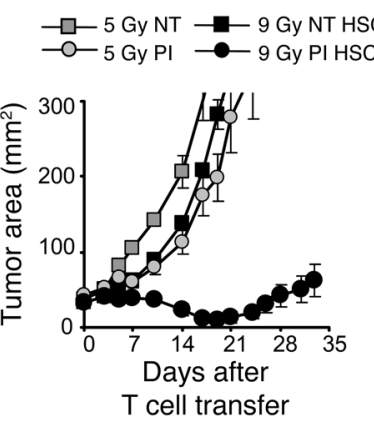

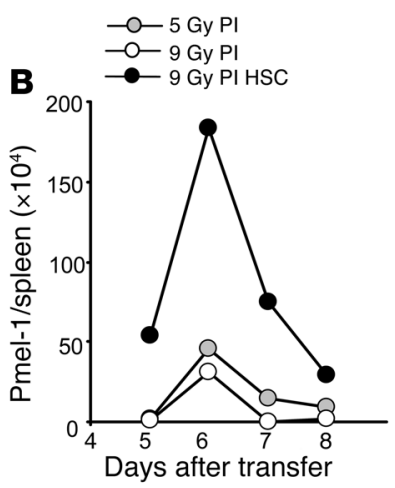

C

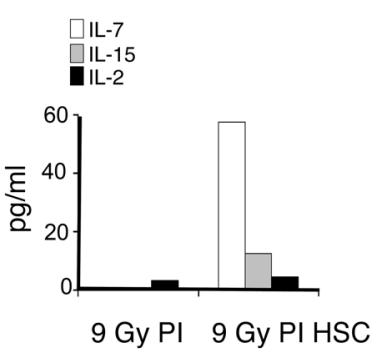

Figure 1

Myeloablative TBI (9 Gy) with HSC transplant significantly enhances ACT and drives T cell expansion. (A) Increasing a nonmyeloablative regimen to a myeloablative one augmented ACT-mediated tumor treatment. C57BL/6 tumor-bearing mice were irradiated with 5 Gy or 9 Gy and received an HSC transplant (HSC); were left untreated as a control (NT); or received transfer of $1 \times 10^{6}$ effector pmel-1 $\mathrm{CD}^{+} \mathrm{T}$ cells and rhIL-2 (PI). Tumor treatment efficacy was strongly improved in myeloablated mice $(P=0.0036 ; 5$ Gy PI versus 9 Gy PI HSC). Results for tumor area are the mean of measurements from 6 mice per group $( \pm$ SEM). Data are representative of 3 independent experiments. (B) HSC transplant drives the proliferation of transferred pmel-1 CD8 ${ }^{+} \mathrm{T}$ cells in a myeloablated host. Cultured genemarked $\left(\right.$ Thy $\left.1.1^{+}\right)$pmel- 1 CD $8^{+}$T cells $\left(1 \times 10^{6}\right)$ were transferred with rhIL-2 into a nonmyeloablated or myeloablated host with or without an HSC transplant. At indicated days, the absolute numbers of adoptively transferred $\mathrm{CD} 8^{+} \mathrm{T}$ cells in the spleen of tumor-bearing mice were analyzed. Data shown represent 3 mice pooled per group. The experiment was performed 3 times, with similar results. (C) Increased serum levels of IL-7 and IL-15 were measured on day 5 after the HSC transplant in C57BL/6 mice by LINCOplex analysis. Data represent 3 mice pooled per group per time point. The experiment was performed twice, with similar results.

HSC ( $\left(\mathrm{in}^{-} / \mathrm{c}-\mathrm{kit}^{+}\right)$transplant to rescue the mice from lethality. We found that increasing the intensity of lymphodepletion can result in enhanced tumor destruction, a result that has major implications for the design of current ACT-based immunotherapies. Transplantation of HSCs, as part of the myeloablative regimen, significantly enhanced the expansion and the antitumor impact of adoptively transferred self/tumor antigen-reactive $\mathrm{T}$ cells. Based upon this central observation, we investigated the requirements of HSC-driven lymphocyte expansion.

\section{Results}

Myeloablative TBI with HSC transplant significantly enhances adoptive $T$ cell therapy. We have previously reported that a nonmyeloablative conditioning regimen delivered prior to the adoptive transfer of antitumor T cells and IL-2 results in a 51\% objective response in patients with metastatic melanoma (12). We hypothesized that the efficiency of adoptively transferred $\mathrm{CD}^{+} \mathrm{T}$ cells would be enhanced by increasing the intensity of immunodepletion. To maximize lymphopenia, B16 tumor-bearing mice received a myeloablative dose of TBI ( 9 Gy) accompanied by a transplantation of $10^{5} \mathrm{lin}^{-} / \mathrm{c}-\mathrm{kit}^{+}$syngeneic HSCs. Adoptive transfer of preactivated transgenic pmel-1 $\mathrm{CD}^{+} \mathrm{T}$ cells mediated tumor regression that was strikingly better after a myeloablative preparative regimen (9 Gy) than after a preparative regimen that spared the bone marrow (5 Gy) $(P=0.0036,5$ Gy versus 9 Gy; Figure $1 \mathrm{~A})$.

Proliferation of transferred $C D 8^{+} T$ cells into a myeloablated host is driven by the HSC transplant. To evaluate the mechanism accounting for increased tumor treatment in mice receiving ACT after TBI and HSC transplant, the persistence of transferred pmel- $1 \mathrm{CD}^{+} \mathrm{T}$ cells in vivo was assessed. The numbers of pmel- $1 \mathrm{CD}^{+} \mathrm{T}$ cells recovered from

tion of adoptively transferred pmel-1 CD8 $\mathrm{T}$ cells was driven not by a more intense lymphodepletion but by the activities of the HSCs after the 9-Gy regimen, we sought to further analyze the requirements for this proliferation.

HSC-driven $T$ cell proliferation and tumor response are not affected by the activation state of transferred $T$ cells. In our previous work, the antitumor effectiveness of tumor-specific pmel-1 $\mathrm{CD} 8^{+} \mathrm{T}$ cells was dependent on stimulation with cognate antigen in vivo, regardless of whether the pmel- $1 \mathrm{CD} 8^{+} \mathrm{T}$ cells were naive or activated prior to their adoptive transfer $(6,22,23)$. While lymphodepletion with a nonmyeloablating (5-Gy) regimen prior to ACT improved the efficacy of tumor treatment, antigen stimulation in vivo by a vaccine remained an absolute requirement for tumor treatment (9). However, vaccine was not necessary in order to induce significant tumor treatment when we transferred pmel- $1 \mathrm{CD} 8^{+} \mathrm{T}$ cells into mice receiving a more intensive preparative regimen (9 Gy TBI) that were reconstituted with an HSC transplant (Supplemental Figure 1; supplemental material available online with this article; doi:10.1172/JCI30414DS1). It appeared that adoptively transferred pmel-1 $\mathrm{CD}^{+} \mathrm{T}$ cells that had been preactivated in vitro became functionally activated in the absence of antigen-specific vaccination in myeloablated animals. Because the experiments represented in Figure 1 employed $\mathrm{CD} 8^{+}$pmel- $1 \mathrm{CD}^{+} \mathrm{T}$ cells that had been stimulated with antigen prior to their adoptive transfer, it remained unclear whether preactivation in vitro was required for HSC-driven expansion. Thus, we evaluated the proliferation and the antitumor efficacy of pmel- $1 \mathrm{CD}^{+} \mathrm{T}$ cells that were naive or preactivated in vitro. In nonmyeloablated (5 Gy) control mice, little proliferation of naive or effector pmel- $1 \mathrm{CD} 8^{+} \mathrm{T}$ cells was observed (Figure 2A, left panel). In contrast, significant proliferation was seen in myeloablated hosts when pmel- $1 \mathrm{CD}^{+} \mathrm{T}$ cells were trans- 

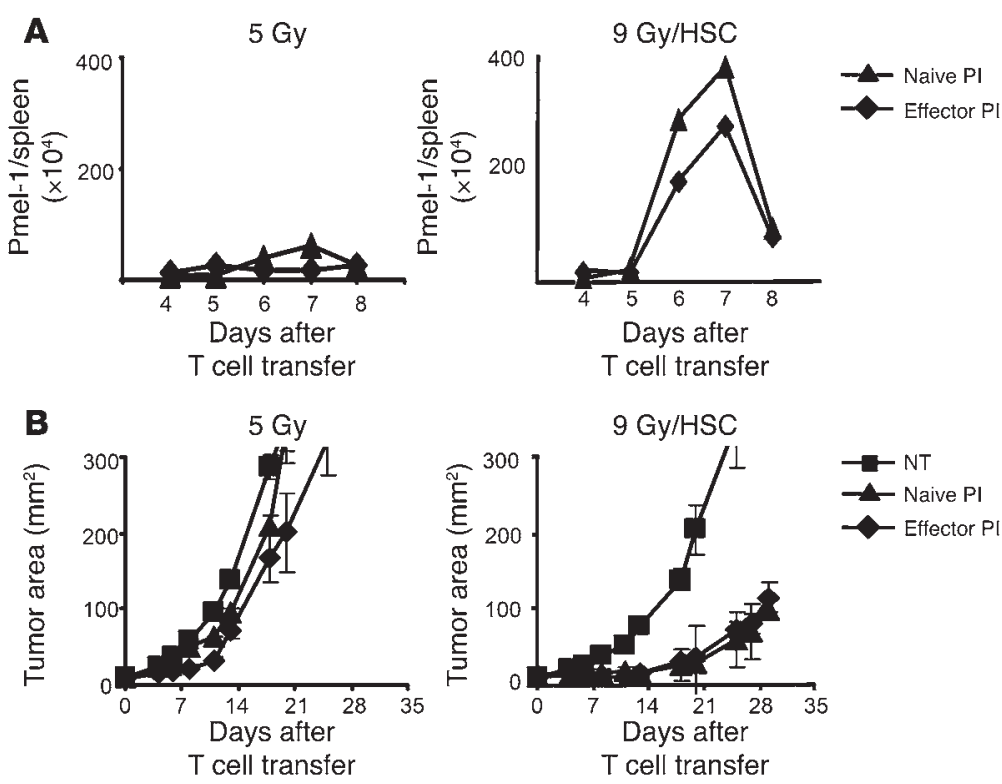

Figure 2

HSCs drive the proliferation and antitumor activity of naive and effector pmel-1 $\mathrm{CD}^{+} \mathrm{T}$ cells in mice treated with a myeloablative preparative regimen and an HSC transplant. (A) The expansion of naive and effector pmel-1 CD8 ${ }^{+} \mathrm{T}$ cells is comparable in myeloablated hosts with HSC transplant. Gene-marked (Thy $\left.1.1^{+}\right)$ naive or effector pmel- $1 \mathrm{CD} 8^{+} \mathrm{T}$ cells $\left(1 \times 10^{6}\right)$ were adoptively transferred with rhIL-2 into a nonmyeloablated host (left panel) or a myeloablated host receiving an HSC transplant (right panel). The absolute numbers of pmel-1 CD8 ${ }^{+} \mathrm{T}$ cells in the spleens of treated animals were enumerated on the days indicated. Spleens of 3 mice per group were pooled at each time point. This experiment was performed 3 times, with similar results. (B) Naive and effector pmel-1 CD8 ${ }^{+} \mathrm{T}$ cells elicit a similar tumor treatment in myeloablated hosts with HSC transplant. Naive or effector pmel-1 CD8 ${ }^{+} \mathrm{T}$ cells $\left(1 \times 10^{6}\right)$ were transferred with rhIL-2 in nonmyeloablated (left panel) or myeloablated hosts with HSC transplant (right panel). Both naive and effector pmel-1 CD8 ${ }^{+} \mathrm{T}$ cells mediated significant tumor treatment $(9 \mathrm{~Gy} / \mathrm{HSC}$ : $P=0.0003$, NT versus naive PI; 9 Gy/HSC: $P=0.0002$, NT versus activated PI; 9 Gy/HSC: $P=0.76$, naive versus effector $\mathrm{PI}$ ), but no tumor treatment was seen in nonmyeloablated animals. Results for tumor area are the mean of measurements from 5 mice per group $( \pm$ SEM).

ferred independently of the in vitro preactivation (Figure 2A, right panel). In the nonmyeloablated (5 Gy) host, neither in vitro stimulated nor naive pmel-1 CD8 ${ }^{+} \mathrm{T}$ cells induced significant tumor treatment (Figure 2B, left panel). However, both naive and effector pmel-1 CD8 ${ }^{+} \mathrm{T}$ cells mediated tumor treatment with comparable effectiveness in the myeloablative setting ( 9 Gy/HSC: $P=0.0003$, no treatment $[\mathrm{NT}]$ versus treatment with naive pmel $\mathrm{CD}^{+} \mathrm{T}$ cells and recombinant human IL-2 [rhIL-2] [PI]; 9 Gy/HSC: $P=0.0002$, NT versus effector PI; 9 Gy/HSC: $P=0.76$, naive versus effector PI; Figure 2B). This indicated that pmel-1 $\mathrm{CD}^{+} \mathrm{T}$ cells did not require in vitro preactivation to reach their full antitumor capacity in the myeloablated setting. It is important to note that complete cures were not always observed. Even in the treatment groups in the 9 Gy/HSC setting, the tumor eventually grew. In addition to the intensity of lymphodepletion, the number of cells as well as their differentiation stage significantly impact the tumor treatment capacity of adoptively transferred T cells (22).

HSC-driven pmel-1 CD $8^{+}$T cell expansion requires in vitro or in vivo TCR engagement. The antitumor activity of pmel- $1 \mathrm{CD}^{+} \mathrm{T}$ cells in nonmyeloablated mice was absolutely dependent on vaccine-induced antigen presentation through MHC class I-expressing APCs (22). However, as shown above (Figure 1), in myeloablated mice, ACT mediated tumor destruction in the absence of in vivo vaccination, even when naive pmel-1 CD8 ${ }^{+} \mathrm{T}$ cells were transferred. Because the antitumor reactivity was vaccine independent, we evaluated whether the expression of host MHC class I by endogenous host cells, HSCs, or their progeny APCs was required. We tested this question in mice that lack $\beta_{2^{-}}$ microglobulin $\left(\beta_{2} \mathrm{~m}\right)$ and are virtually devoid of functional MHC class I (24). Transgenic in vitro activated pmel-1 CD8 ${ }^{+} \mathrm{T}$ cells were transferred into $9 \mathrm{~Gy}$-irradiated $\beta_{2}$ m-deficient hosts that had been reconstituted with HSCs derived from WT or $\beta_{2}$ m-deficient donors. The expansion of in vitro activated antitumor $T$ cells was robust in the presence or absence of $\beta_{2} \mathrm{~m}$ (Figure $3 \mathrm{~A}$, left panel). Most importantly, significant tumor treatment was observed in HSC-transplanted, myeloablated hosts in the absence of $\beta_{2} \mathrm{~m}$ (Figure 3A, right panel; 9 Gy in $\beta_{2} \mathrm{~m}^{-/-}$mice: $P=0.001$, NT versus effector PI). This tumor treatment efficacy was comparable to that seen in myeloablated WT mice that received an HSC transplant (Figure 3A, right panel; 9 Gy effector PI: $P=0.9$, WT versus $\beta_{2} \mathrm{~m}^{-/-}$).

We next tested the in vivo activities of naive $\mathrm{CD}^{+}$ $\mathrm{T}$ cells compared with antigen-experienced effector $\mathrm{CD}^{+} \mathrm{T}$ cells in myeloablated mice lacking $\beta_{2} \mathrm{~m}$ expression transplanted with $\beta_{2} \mathrm{~m}^{-/-}$HSCs (Figure $3 \mathrm{~B}$ ). In sharp contrast to the functional activities of preactivated effector cells adoptively transferred into hosts lacking $\beta_{2} \mathrm{~m}$ (Figure $3 \mathrm{~A}$ ), adoptively transferred naive pmel-1 CD8 ${ }^{+} \mathrm{T}$ cells did not proliferate (Figure 3B, left panel) and did not mediate a measurable therapeutic impact in the tumor-bearing setting (Figure 3B, right panel; $P=0.96$, NT versus naive PI). Thus, while activated cells can proliferate and destroy tumor in the absence of host $\beta_{2}$ m expression, naive cell proliferation and function were dependent on the expression of $\beta_{2} \mathrm{~m}$ by the host. This result showed that the HSC-driven proliferation and antitumor function required $\mathrm{MHC}$ class I-dependent TCR triggering of the transferred pmel-1 CD8 ${ }^{+}$ $\mathrm{T}$ cells and that TCR triggering of pmel- $1 \mathrm{CD}^{+} \mathrm{T}$ cells could be accomplished either in vivo or in vitro.

HSCs drive pmel-1 CD8 $8^{+}$cell expansion but not tumor response in nonmyeloablated mice. HSC-driven proliferation of pmel-1 $\mathrm{CD}^{+} \mathrm{T}$ cells was observed after 9 Gy TBI, in which case these HSCs were required for host survival after myeloablation (Figure 1B), but it was unclear whether HSCs would drive the expansion of $\mathrm{CD}^{+}$ $\mathrm{T}$ cells when they were given after a nonmyeloablative preparative regimen, where they were not required to rescue mice from lethality. HSCs were transplanted after 5 Gy TBI, and levels of transferred pmel-1 transgenic T cells in the spleen were analyzed. HSCs increased the proliferation of pmel- $1 \mathrm{CD}^{+} \mathrm{T}$ cells in the nonmyeloablative (5-Gy) setting (Figure 4A). This proliferation was equivalent to that seen in mice receiving an HSC transplant after 9 Gy TBI. The kinetics of HSC-driven pmel- $1 \mathrm{CD}^{+} \mathrm{T}$ cell expansions were similar to those seen in the 9-Gy TBI setting. These results were seen reproducibly upon analysis of individual mice (Figure 4B; $P=0.02$, 5 Gy versus 5 Gy/HSC; $P=0.0009$, 9 Gy versus $9 \mathrm{~Gy} / \mathrm{HSC}$; $P=0.24,5 \mathrm{~Gy} / \mathrm{HSC}$ versus $9 \mathrm{~Gy} / \mathrm{HSC})$. Surpris- 

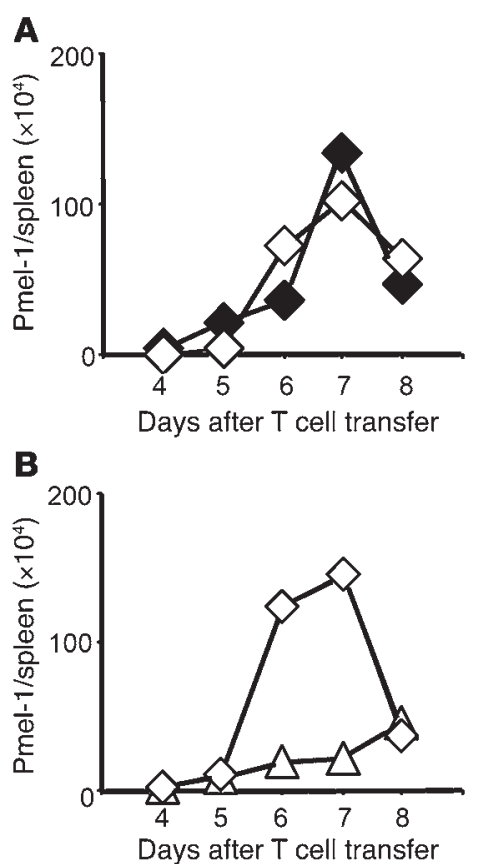

Figure 3

HSCs drive effector, but not naive, pmel-1 CD8 ${ }^{+} \mathrm{T}$ cell expansion and tumor treatment in the absence of host $\beta_{2} \mathrm{~m}$. (A) HSC-driven effector pmel-1 CD8 ${ }^{+} \mathrm{T}$ cell expansion and tumor treatment is MHC class I independent. Effector pmel-1 CD8 ${ }^{+}$T cells $\left(1 \times 10^{6}\right)$ were transferred together with rhlL-2 into 9-Gy irradiated $\beta_{2} \mathrm{~m}^{-/-}$or WT mice that had received the matched HSC transplant and had 10-day established B16 tumors. T cell expansion (left panels) and tumor treatment (right panels) were evaluated at the indicated days. Control groups were left untreated. Effector pmel-1 CD8 ${ }^{+} \mathrm{T}$ cells showed similar proliferation and tumor treatment in $\beta_{2} \mathrm{~m}^{-/-}$and WT mice (9 Gy effector PI: $P=0.9$, WT versus $\beta_{2} \mathrm{~m}^{-1-} ; 9$ Gy in $\beta_{2} \mathrm{~m}^{-1-}: P=0.001$, NT versus effector $\mathrm{Pl}$ ). (B) In $\beta_{2} \mathrm{~m}^{-/-}$mice, only effector, but not naive, pmel-1 CD8 ${ }^{+}$showed HSC-driven T cell expansion and tumor treatment. Effector or naive pmel-1 CD8 ${ }^{+} \mathrm{T}$ cells were transferred into myeloablated tumor-bearing $\beta_{2} \mathrm{~m}^{-/-}$mice receiving a $\beta_{2} \mathrm{~m}^{-/-} \mathrm{HCS}$ transplant. Naive pmel-1 CD8 ${ }^{+} \mathrm{T}$ cells showed neither proliferation nor significant tumor treatment $(P=0.96$, NT versus naive $\mathrm{Pl})$. Proliferation curves represent the numbers of gene-marked pmel-1 CD8+ T cells found in the spleens of 3 mice pooled per group per time point. Results for tumor area are the mean of measurements from 5 mice per group $( \pm$ SEM). The data shown are representative of 3 independently performed experiments.

ingly, the HSC-driven expansion observed in the nonmyeloablative setting did not result in enhanced antitumor activity (Figure 4C; $P=0.22,5$ Gy versus 5 Gy/HSC). Thus, the HSC-induced spike in antitumor $\mathrm{T}$ cell number was not associated with measurable tumor destruction. Although myeloablation was not essential for HSC-driven $\mathrm{T}$ cell proliferation, it was important for the translation into effective tumor treatment. We previously reported that Tregs and cellular sinks for cytokines could inhibit the antitumor activities of adoptively transferred $\mathrm{CD}^{+} \mathrm{T}$ cells $(9,17)$. We hypothesized that HSCs might not only cause the expansion of adoptively transferred T cells, but might also provide support for host cells that survive 5 Gy TBI, including cells capable of restraining the antitumor immune response.

HSCs drive host cells surviving TBI that hinder the effectiveness of antitumor T cells. To determine the impact of HSCs on host immune cells that survived lymphodepletion, we analyzed the number of a variety of cellular subsets in the spleen after nonmyeloablative (5 Gy) and myeloablative (9 Gy) irradiation. Myeloablative conditioning regimens reduced the number of cells present 5 days after irradiation compared with the nonmyeloablative condition (Figure 5A). We observed that an HSC transplant increased the numbers of $\mathrm{CD}^{+}{ }^{+} \mathrm{T}$ cells, $\mathrm{Gr} 1^{+}$ cells, NK cells, and B cells in both the 5-Gy and 9-Gy settings. Thus, HSCs supported the expansion of not only adoptively transferred $\mathrm{CD}^{+} \mathrm{T}$ cells but a variety of endogenous host cells as well (Figure 5A). Because HSCs can differentiate into each of the above-mentioned cell types (25), we sought to determine whether these different immune cells were derivatives from the HSCs or were host cells that had survived TBI. Studies using congenic markers indicated that virtually all lymphocytes obtained 7 days after the transplant were derived from host cells that survived TBI (Figure 5B). Thus, HSCs drove the proliferation of adoptively transferred transgenic $\mathrm{CD}^{+} \mathrm{T}$ cells and increased the numbers of splenic lymphocytes not via progeny cells but by promoting the expansion of endogenous host cells. These expanded endogenous lymphocyte compartments included inhibitory elements such as $\mathrm{CD}^{+}{ }^{+} \mathrm{CD} 25^{+} \mathrm{Foxp}^{+}$ Tregs, as well as endogenous $\mathrm{CD}^{+} \mathrm{T}$ cells and NK cells. $\mathrm{CD} 4{ }^{+} \mathrm{CD} 25^{+} \mathrm{Foxp}^{+}$Tregs have been shown to negatively modulate the functionality of adoptively transferred tumor-reactive $\mathrm{CD}^{+} \mathrm{T}$ cells, resulting in diminished treatment efficacy $(17,18,26,27)$. Endogenous CD8 ${ }^{+}$ $\mathrm{T}$ and NK cells can act as cellular sinks for homeostatic cytokines and compete for these cytokines with the adoptively transferred tumor-reactive $\mathrm{CD}^{+} \mathrm{T}$ cells, thereby reducing the efficacy of tumor treatment mediated by the transferred tumor-reactive $\mathrm{CD}^{+} \mathrm{T}$ cells (9, 28-30). Thus, HSC transplantation increased the levels of surviving endogenous host cells that might have abrogated pmel-1 $\mathrm{CD}^{+} \mathrm{T}$ cell antitumor efficacy.

To directly test whether these surviving host cells were capable of negatively influencing pmel-1 CD8 ${ }^{+} \mathrm{T}$ cell-mediated tumor destruction, we measured the treatment efficacy of adoptively transferred pmel-1 CD8 ${ }^{+} \mathrm{T}$ cells in WT hosts and hosts that were genetically deficient in lymphocyte subsets. Biological differences in the tumor treatment efficacy emerged when suboptimal numbers of adoptively transferred T cells were transferred (Figure 5C). Treatment was improved in myeloablated mice that were knockouts for CD4 $\left(P=0.017,9\right.$ Gy PI WT versus $\left.9 \mathrm{~Gy} \mathrm{CD}^{-/-}\right)$, CD8 $\left(P=0.004,9\right.$ Gy PI WT versus $\left.9 \mathrm{~Gy} \mathrm{CD}^{-/-}\right)$, as well as RAG $(P=0.0017$, 9 Gy PI WT versus $9 \mathrm{~Gy} \mathrm{RAG}^{-/-}$) (Figure 5C). These findings indicated that surviving host cells, even after 9 Gy TBI, were able to reduce the 
A

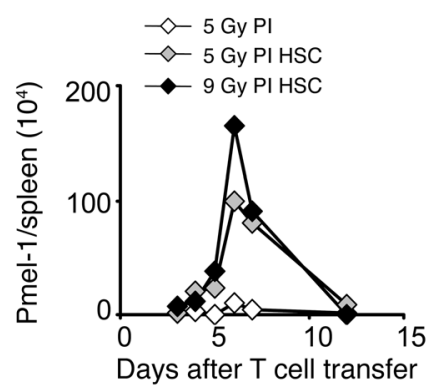

B

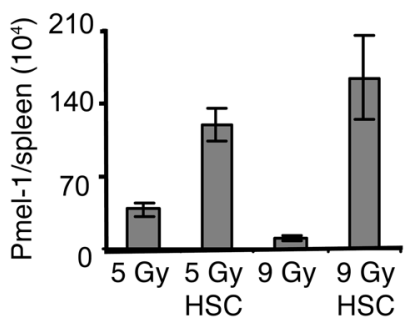

C -5 Gy NT $\prec-5$ Gy PI $\neg-5$ Gy NT HSC $\prec-5$ Gy PI HSC -9 Gy NT HSC $\multimap 9$ Gy PI HSC

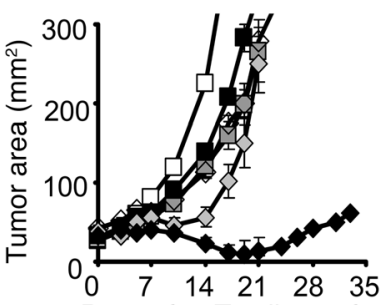

Days after $\mathrm{T}$ cell transfer

\section{Figure 4}

HSCs drive pmel-1 CD8 ${ }^{+} \mathrm{T}$ cell expansion in nonmyeloablated and myeloablated mice, but tumor treatment is only achieved in myeloablated mice. (A and B) HSC transplantation-driven transgenic T cell expansion is not dependent on the intensity of immunodepletion. Mice received a preparative regimen of either $5 \mathrm{~Gy}$ or 9 Gy TBI, which was followed by effector pmel-1 CD8+ T cells $\left(1 \times 10^{6}\right)$ and rhIL-2 with or without HSC transplantation. (A) Absolute numbers of adoptively transferred congenic marked pmel-1 CD8 ${ }^{+} \mathrm{T}$ cells in the spleen were enumerated on the days indicated. Results shown were derived from pooled splenocytes of 3 mice per group per time point (A) or from 3 individual mice $( \pm$ SEM) assessed on day $6(\mathbf{B})(P=0.0009,9$ Gy versus $9 \mathrm{~Gy} / \mathrm{HSC} ; P=0.02,5$ Gy versus $5 \mathrm{~Gy} / \mathrm{HSC} ; P=0.24,5 \mathrm{~Gy} / \mathrm{HSC}$ versus $9 \mathrm{~Gy} / \mathrm{HSC}$ ). (C) HSC-driven expansion of pmel-1 CD8 ${ }^{+}$T cells is therapeutically effective in myeloablated, but not in nonmyeloablated, WT mice. Animals bearing tumors established for 10 days were either left as controls (NT) or received, prior to the transfer of $1 \times 10^{6}$ effector pmel-1 CD8+ T cells and rhIL-2, either 5 Gy TBI, 5 Gy TBI and an HSC transplant, or $9 \mathrm{~Gy} \mathrm{TBI}$ and an HSC transplant. Results for tumor area are the mean of measurements from 5 mice per group $( \pm$ SEM). Results for each of the panels are representative of data from 3 independent experiments.

effectiveness of pmel-1 CD8 ${ }^{+} \mathrm{T}$ cell tumor treatment. Endogenous $\mathrm{CD} 4^{+} \mathrm{T}$ cells, which contain Tregs, and endogenous $\mathrm{CD} 8^{+} \mathrm{T}$ cells were able to negatively impact the pmel- $1 \mathrm{CD}^{+} \mathrm{T}$ cell tumor treatment capacity. An inhibitory role for NK1.1 $1^{+}$cells was not detected in the myeloablative setting (data not shown) but was revealed by their depletion in nonmyeloablated $\mathrm{RAG}^{-/}$hosts $(P=0.01$; 5 Gy PI RAG ${ }^{-/}$ISO versus 5 Gy PI RAG ${ }^{-/-} \alpha-\mathrm{NK}$; Figure 5D). Thus, endogenous host cells strongly influenced the tumor treatment capacity of transferred $\mathrm{CD}^{+} \mathrm{T}$ cells even when they were present in small numbers as a result of TBI-mediated immunodepletion.

The antitumor $T$ cell/host cell ratio determines tumor treatment outcome. We evaluated the impact of the nonmyeloablative (5-Gy) and myeloablative (9-Gy) preparative regimens on the ratios of effector pmel- $1 \mathrm{CD}^{+} \mathrm{T}$ cells to remaining inhibitory elements (Foxp $3^{+} \mathrm{CD} 4^{+}$ cells, $\mathrm{CD}^{+}$cells, and NK1.1 $1^{+}$cells). Three congenic markers were used to identify the ablated host cells $\left(\right.$ Thy $\left.1.2^{+}\right)$in mice that received TBI followed by HSC transplantation (Thy $1.1^{+}$) with the adoptive transfer of preactivated pmel-1 CD8 ${ }^{+} \mathrm{T}$ cells $\left(\right.$ Ly5 $\left..1^{+}\right)$ (Figure 6, A and B, left and right panels). We found that compared with mice receiving a nonmyeloablative regimen without HSC transplant, mice receiving myeloablative TBI with HSC transplant had significantly higher ratios of transferred pmel-1 effector $\mathrm{CD}^{+}$ $\mathrm{T}$ cells to host regulatory elements including Foxp $3{ }^{+} \mathrm{CD} 4^{+}$Tregs $(P=0.0006,5$ Gy versus $9 \mathrm{~Gy} / \mathrm{HSC}), \mathrm{CD}^{+} \mathrm{T}$ cells $(P=0.003,5 \mathrm{~Gy}$ versus $9 \mathrm{~Gy} / \mathrm{HSCs})$, and NK1.1 $1^{+}$cells $(P=0.0006,5$ Gy versus $9 \mathrm{~Gy} /$ HSC) (Figure 6B). When HSCs were transferred into the nonmyeloablated and myeloablated animals, the ratios of antitumor $T$ cells to host immunoregulatory cells still remained greater after 9 Gy TBI. Although the total number of pmel- $1 \mathrm{CD}^{+} \mathrm{T}$ cells was comparable in myeloablated and nonmyeloablated animals with an HSC transplant, the ratios were significantly in favor of the transferred pmel-1 $\mathrm{CD}^{+} \mathrm{T}$ cells in the myeloablated animals, measured for pmel-1 $\mathrm{CD}^{+} \mathrm{T}$ cells versus Foxp $3^{+} \mathrm{CD} 4{ }^{+}$Tregs $(P=0.0005,5$ Gy/HSC verresult in an enhanced tumor treatment if there are no or few inhibitory elements to be driven by the HSC transplant. In this scenario, the HSC transplant increases the number of transferred T cells but not of inhibitory elements, since they are genetically removed. Pmel-1 CD8 ${ }^{+} \mathrm{T}$ cells were transferred with an HSC transplant into $\mathrm{RAG}^{-/-}$hosts, which are genetically lymphodepleted (Figure 6B). Giving an HSC transplant in $\mathrm{RAG}^{-/-}$mice significantly augmented the efficacy of tumor-reactive pmel- $1 \mathrm{CD}^{+} \mathrm{T}$ cells in a nonmyeloablated (5-Gy irradiated) host $\left(P=0.038,5 \mathrm{~Gy} \mathrm{PI} \mathrm{RAG}^{-/-}\right.$versus 5 Gy PI RAG ${ }^{-/-}$HSC; Figure 6B) but not in control WT mice in the same experiment (data not shown). These results confirmed the hypothesis that enhanced treatment can be achieved by focusing HSC support on transferred pmel- $1 \mathrm{CD}^{+} \mathrm{T}$ cells in an environment where regulatory elements are genetically reduced. The antitumor capacity of the transferred pmel- $1 \mathrm{CD}^{+} \mathrm{T}$ cells correlated with the amount of autoimmune vitiligo resulting from the destruction of normal melanocytes that express gp100, the target antigen of pmel-1 CD8 ${ }^{+} \mathrm{T}$ cells (Figure 6C). Thus, HSCs drove the expansion of transferred tumor-reactive $\mathrm{T}$ cells in both 5-Gy and 9-Gy regimens but 9 Gy TBI mediated a more complete depletion of endogenous host cells, focusing the HSC-mediated lymphocyte expansion on the adoptively transferred antitumor cells.

\section{Discussion}

Endogenous host cells can impact the functionality of adoptively transferred tumor-reactive $T$ cells and can negatively influence their tumor treatment capacity $(9,17,18)$. A regimen in which endogenous host cells are removed by nonmyeloablative, lymphodepletion conditioning has been used successfully in mice and in patients to enhance the antitumor efficacy of adoptively transferred $T$ cells $(9,12)$. Increasing the lymphodepletion to achieve a myeloablative regimen requiring an HSC transplant significantly augmented tumor treatment. The aug- 


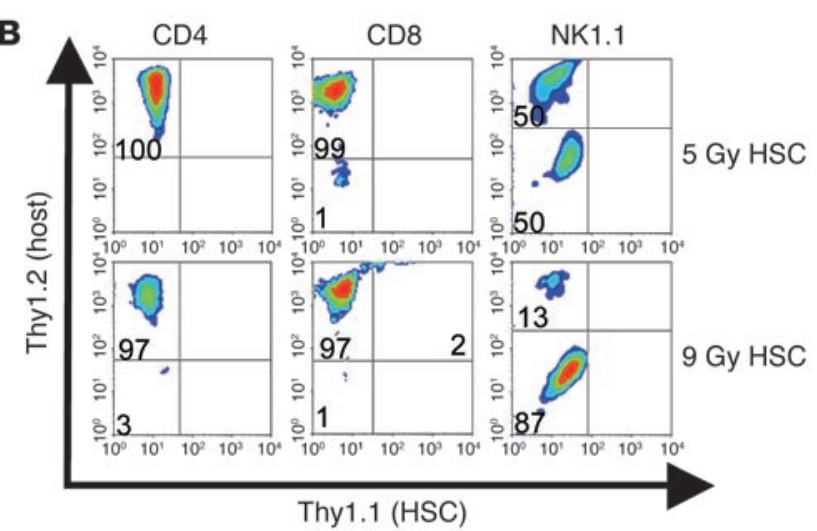

C

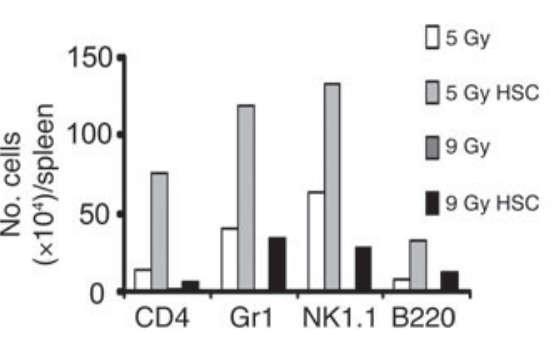

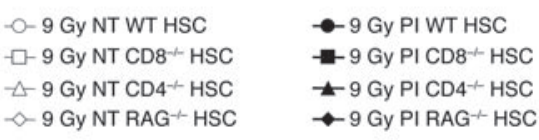

D
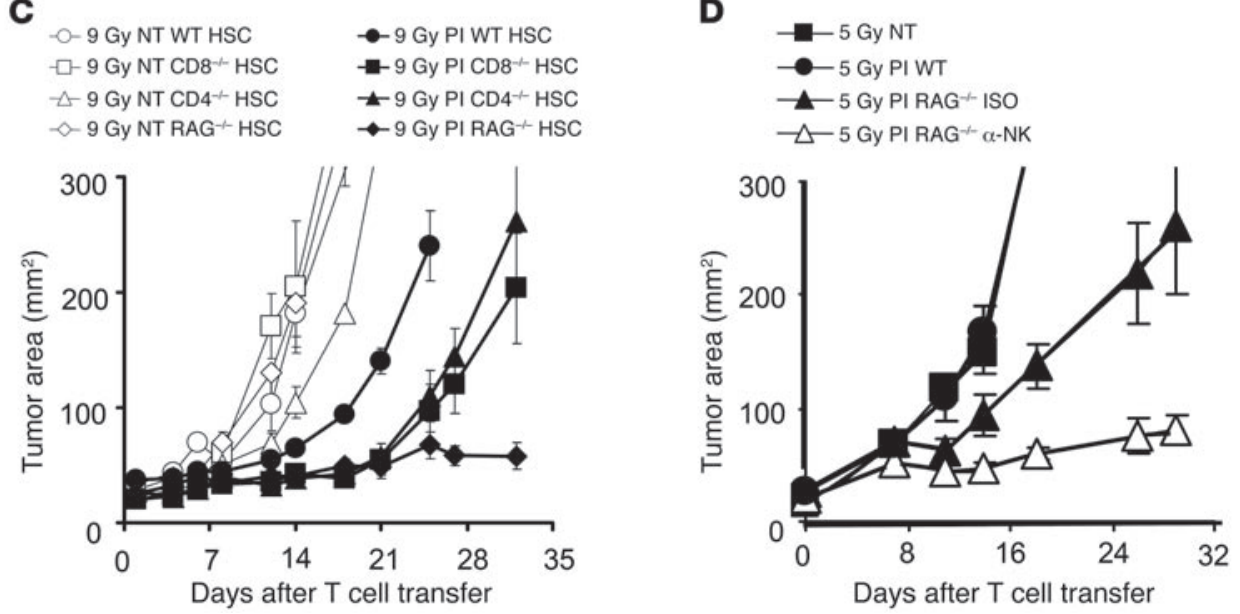

\section{Figure 5}

HSCs drive expansion of host cells surviving TBI, hindering the effectiveness of antitumor T cells. (A) HSC transplants increase the numbers of splenic $\mathrm{CD} 4^{+} \mathrm{T}$ cells and $\mathrm{Gr}-1^{+}, \mathrm{NK}$, and $\mathrm{B}$ cells found in irradiated mice. Absolute numbers of splenic $\mathrm{CD} 4^{+}, \mathrm{Gr} 1^{+}, \mathrm{NK} 1.1^{+}$, or B220+ cells were determined 5 days after mice received 5 Gy or 9 Gy TBI with or without HSC transplant. Mice received $1 \times 10^{6}$ pmel- 1 CD $8^{+}$T cells and rhIL-2. (B) HSC-driven recovery is derived from host cells, not HSC progeny. Thy $1.1^{+} \mathrm{HSC}$ sere transplanted into Thy $1.2^{+}$hosts that had received either 5 Gy or 9 Gy TBI and rhIL-2. Data shown are from 3 pooled spleens per group at day 7. (C and D) Returning host cells can abrogate pmel-1 CD8+ T cell tumor treatment. (C) Tumor-bearing myeloablated WT, CD4 ${ }^{--}, \mathrm{CD}^{-/-}$, or RAG ${ }^{-/-}$mice with a syngeneic HSC transplant were left untreated as control or received suboptimal amounts $\left(5 \times 10^{5}\right)$ of effector pmel-1 CD8+ T cells with rhIL-2. $P=0.017,9$ Gy PI WT versus 9 Gy CD4 ${ }^{-1-}$; $P=0.004,9$ Gy PI WT versus 9 Gy CD8 ${ }^{-/-} ; P=0.0017,9$ Gy PI WT versus 9 Gy RAG $^{-1-}$. (D) Tumor-bearing nonmyeloablated WT or RAG ${ }^{-/-}$mice were left untreated as control or received $1 \times 10^{6}$ effector pmel-1 CD8 ${ }^{+}$T cells and rhIL-2. NK1.1 cell-depleting ( $\alpha$-NK) or isotope control (ISO) antibodies were given every 5 days, starting at day 0 and ending on day $20\left(P=0.01,5\right.$ Gy PI RAG ${ }^{--}$ISO versus 5 Gy PI RAG $\left.{ }^{-/-} \alpha-\mathrm{NK}\right)$. Results for tumor area are the mean of measurements from 5 mice per group $( \pm S E M)$. Data are representative of 3 experiments.

mented tumor treatment efficacy was associated with increased antitumor $\mathrm{T}$ cell expansion. The reason for the increased $\mathrm{T}$ cell proliferation was not merely the lymphopenic environment in myeloablated animals but the HSC transplant, which induced the expansion of transferred tumor-reactive pmel-1 $\mathrm{CD}^{+} \mathrm{T}$ cells. This was also the case in the nonmyeloablative setting, but tumor treatment was only seen when the HSCs were transferred into myeloablated animals. The expansion of antitumor $\mathrm{T}$ cells with tumor destruction can also be triggered by antigenspecific vaccination (6). While vaccination preferentially drives the expansion of antitumor T cells, HSCs drive tumor-specific T cells and endogenous host immunoregulatory cells with equal vigor. Even in very small numbers, these host cells inhibit the antitumor activity of pmel-1 $\mathrm{CD}^{+} \mathrm{T}$ cells. Thus, myeloablation significantly reduces the number of surviving host cells, drastically shifting the ratio of tumor-reactive pmel-1 $\mathrm{CD}^{+} \mathrm{T}$ cells to endogenous host cells in favor of the pmel-1 CD8 ${ }^{+} \mathrm{T}$ cells, allowing improved tumor treatment. The ratio of effector to suppressor cells has been recently proposed to be a predictor of tumor treatment outcome in mice (31) and survival in patients with ovarian cancer $(32,33)$. Besides CD $4^{+} \mathrm{CD} 25^{+} \mathrm{Foxp}^{+}$ Tregs, CD $11 \mathrm{~b}^{+} \mathrm{Gr} 1^{+}$myeloid suppressor cells (MSCs) have been described to suppress the functionality of tumor-specific $\mathrm{T}$ lymphocytes (34-36). By increasing the intensity of ablation, the level of MSCs in the tumor might be decreased, leading to improved tumor treatment. In addition to lowering levels of suppressive elements, intensive lymphodepletion also reduces the numbers of endogenous host cells such as $\mathrm{CD}^{+}$and $\mathrm{NK}$ cells, which consume homeostatic cytokines, thereby leading to elevated levels of IL-7 and IL-15. Additionally we showed that an HSC transplant in 9-Gy irradiated animals also increased the level of theses cytokines in the serum. IL-7 and IL-15 are main inducers of homeostatic $T$ cell proliferation and activation and can impact the transferred $T$ cells. Thus, the interaction of the 


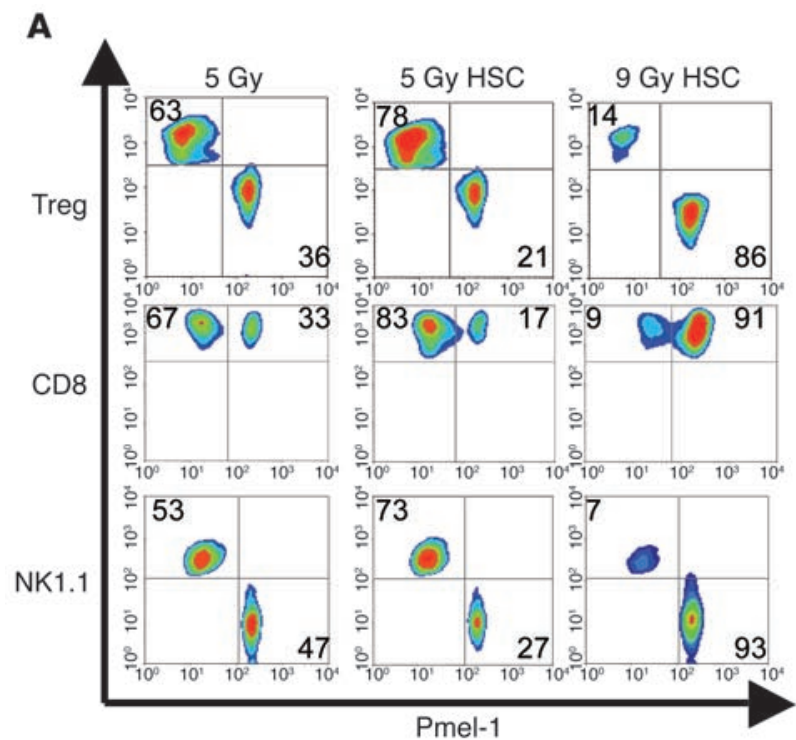

B

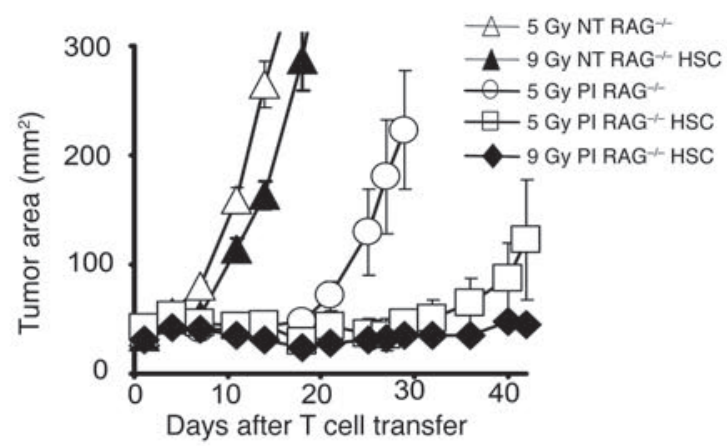

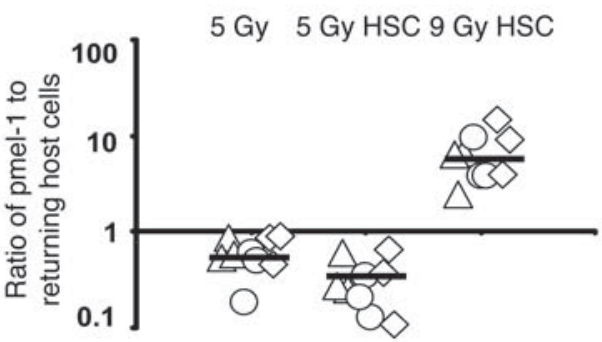

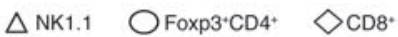

C

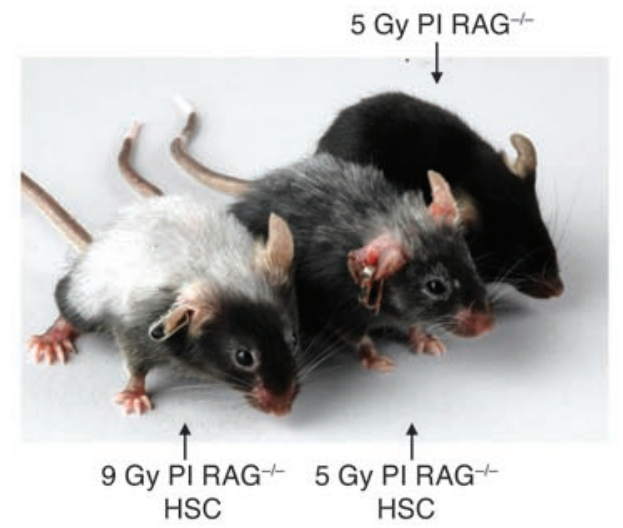

Figure 6

The antitumor effectiveness of HSC-driven CD8 ${ }^{+}$T cell proliferation is dependent on the reduction of host inhibitory elements. (A and B) Ratios of adoptively transferred effector pmel-1 CD8+ $\mathrm{T}$ cells $\left(\mathrm{CD} 8^{+} \mathrm{Ly} 5.1^{+}\right)$relative to returning host Treg cells (Foxp3+CD4+), host CD8+Th1.1+ cells, and host NK1.1+ cells are shifted toward pmel-1 CD8 ${ }^{+} \mathrm{T}$ cells in myeloablated mice. Thy $1.2^{+}$host mice received a preparative regimen of 5 Gy or 9 Gy with an HSC transplantation from Thy $1.1^{+}$mice, which was followed by the adoptive transfer of $1 \times 10^{6}$ effector $\left(\right.$ Ly5.1+) pmel-1 CD8 ${ }^{+} \mathrm{T}$ cells and rhIL-2. Control mice received 5 Gy TBI in the absence of an HSC transplant. Splenocytes obtained 1 week after HSC transplant were simultaneously analyzed for adoptively transferred gene-marked pmel-1 CD8 ${ }^{+}$and reconstituting host cells (left panel). Flow cytometry data from pooled splenocytes from 3 mice were used to calculate the ratios of adoptively transferred pmel- 1 CD $8^{+} \mathrm{T}$ cells, and cumulative results from 3 independent experiments ( 3 mice per experiment) are shown in the right panel. The ratios of transferred pmel- $1 \mathrm{~T}$ cells to host immune cell subsets were significantly higher after 9 Gy TBI with an HSC transplant than after 5 Gy irradiation with or without an HSC transplant. The levels of significance are as follows: for of NK cells $(P=0.0006,5$ Gy versus $9 \mathrm{~Gy} / \mathrm{HSC}, P=0.0005,5 \mathrm{~Gy} / \mathrm{HSC}$ versus $9 \mathrm{~Gy} / \mathrm{HSC})$, Foxp3 $3^{+} \mathrm{CD} 4+$ Tregs $(P=0.0006,5$ Gy versus $9 \mathrm{~Gy} / \mathrm{HSC}, P=0.0005,5 \mathrm{~Gy} / \mathrm{HSC}$ versus $9 \mathrm{~Gy} / \mathrm{HSC})$ and CD8+ T cells $(P=0.003,5 \mathrm{~Gy}$ versus $9 \mathrm{~Gy} / \mathrm{HSC}$, $P=0.002,5 \mathrm{~Gy} / \mathrm{HSC}$ versus $9 \mathrm{~Gy} / \mathrm{HSC}$ ). (B) HSC-driven pmel-1 CD8 ${ }^{+}$T cell proliferation can augment tumor treatment in RAG ${ }^{-/-}$mice. RAG ${ }^{-/-}$ mice bearing 10-day tumors were irradiated with 5 Gy or 9 Gy with or without an HSC transplant and were treated with $1 \times 10^{6}$ effector pmel-1 $\mathrm{CD}^{+} \mathrm{T}$ cells with rhlL-2. Control mice were left untreated. Data are representative of 3 independent experiments, each with 5 mice per group. (C) Tumor treatment efficacy is associated with the severity of vitiligo observed 28 days after pmel-1 CD8 ${ }^{+}$T cell transfer.

HSC transplant with the adoptively transferred T cells is likely to impact the quality of the $\mathrm{T}$ cells, but the exact changes in the quality of the transferred $\mathrm{T}$ cells remain to be elucidated.

TBI may facilitate tumor destruction by a variety of factors in addition to immune depletion. Irradiation, especially intensive radiation, can directly damage tumor cells and supporting tumor stroma. However, we have previously shown that local irradiation of the B16 tumor up to 10 Gy does not significantly impact on the tumor growth and does not improve the activity of adoptively transferred TCR-restricted T cells (9). Furthermore, chemotherapeutic agents as well as irradiation are described to modulate the immunogenicity of tumor cells in mouse and human. Irradiation reportedly upregulates the expression of surface molecules such as MHC class I, Fas, and ICAM-1 (37), which can enhance tumor recognition by adoptively transferred $\mathrm{T}$ cells. In addition, irradiation can modify the peptide repertoire, increase peptide production and antigen presentation, and enhance MHC class I expression by tumor cell lines (38). This might have particular relevance to tumor recognition by endogenous host cells with an open repertoire. Thus, increas- 
ing the intensity of the TBI or chemotherapy-based preparative regimen may enhance the efficacy of immunotherapies based on the adoptive transfer of antitumor $\mathrm{T}$ cells through a variety of mechanisms; importantly, the use of more intense myeloablative regimens must be balanced against their toxicities (39).

Previous work has shown that nonmyeloablative lymphodepletion significantly increased the efficacy of ACT given in combination with IL-2 (9); however, vaccination with an altered-self ligandbased vaccine was required. Thus, the lymphopenia induced by the regimens previously employed did not activate adoptively transferred antitumor $\mathrm{CD}^{+} \mathrm{T}$ cells to a level required to mediate the treatment of established tumor $(6,9,17)$. Surprisingly, vaccination was not required in the setting of a myeloablative conditioning regimen prior to ACT-based immunotherapy (Supplemental Figure 1). Why did the requirements for $\mathrm{T}$ cell activation change so dramatically when the preparative regimen was increased from 5 Gy TBI to 9 Gy TBI? The most likely scenario was that a more intensive lymphodepletion resulted in a more complete depletion of cellular cytokine sinks and $\mathrm{CD} 4{ }^{+} \mathrm{CD} 25^{+} \mathrm{Foxp} 3^{+}$Tregs. Indeed, we found that although cells of hematopoietic origin were depleted by a nonmyeloablative TBI regimen ( $5 \mathrm{~Gy}$ ), the administration of a myeloablative dose of TBI depleted host endogenous myeloid and lymphoid cells an additional 10-fold.

Vaccine independence may be a critical feature in the translation of these findings to ACT-based therapies in humans, as vaccines for adoptively transferred, polyclonal $\mathrm{T}$ cells are not always available. In humans, tumor-reactive $\mathrm{T}$ cells are usually derived from tumor-infiltrating lymphocytes (TILs) that are expanded ex vivo using IL-2. TILs are further selected by their ability to specifically secrete IFN- $\gamma$ when cultured with autologous or allogeneic MHCmatched tumor cell lines. Before tumor-reactive TILs are transferred into the patient, they are expanded using CD3-specific antibodies, IL-2, and irradiated allogeneic peripheral-blood mononuclear feeder cells (1). Approximately $50 \%$ of the tumor-reactive TILs have specificity against epitopes from unknown cancer antigens. In the absence of suitable vaccines, tumor-reactive $\mathrm{CD}^{+} \mathrm{T}$ cells can be activated and expanded in vivo upon transfer into an HSC-transplanted, myeloablated host.

In the field of antiviral immunotherapy, valuable experience has been gained in the transfer of antigen-specific T cells into highly lymphodepleted patients with an autologous bone marrow transplant. Patients who are lymphopenic after organ or bone marrow transplant are at high risk for developing CMV- or EBV-mediated disease $(40,41)$. Immunotherapeutic strategies aim to restore the virus-specific cellular immunity by transferring allogeneic or autologous virus-reactive CTLs $(42,43)$, which restored the cellular immune deficiency in highly immune-suppressed patients with limited toxicity and efficiently treat CMV- and EBV-associated disease (40, 44-46). In myeloma patients treated with high-dose chemotherapy and autologous stem cell transplantation, a better clinical outcome was associated with more rapid lymphocyte recovery after the transplant (47). In order to augment the recovery and function of autologous $\mathrm{T}$ cells in myeloma patients, June and colleagues stimulated antigen-primed autologous $T$ cells ex vivo and combined vaccine therapy with adoptive $T$ cell transfer into lymphodepleted patients. They were able to raise clinically relevant immunity in adults within 1 month after transplantation (48).

HSCs are known to provide new progeny cells (25), and HSC transplantation has been used in tumor therapy to rescue bone marrow function after high-dose chemotherapy (49). Depending on the cell type, the recovery time of HSC-derived progeny can take several days to several months, but little is known about how HSCs influence the homeostatic proliferation of endogenous host cells or transferred T cells. In this study, syngeneic HSCs not only provided new progeny, but also supported the proliferation and survival of adoptively transferred self/tumor-reactive $\mathrm{CD} 8^{+} \mathrm{T}$ cells that can mediate tumor destruction. HSC-driven T cell expansion was not limited to myeloablated animals but also could be observed in nonmyeloablated animals that received HSC transplant. By studying the requirements for the HSC-driven T cell expansion, we found that both naive and antigen-experienced $T$ cells underwent HSC-driven expansion similar to homeostatic proliferation $(13,15,16)$. TCR engagement of naive T cells was required because HSC-driven T cell expansion of naive T cells was seen in WT but not in $\beta_{2} \mathrm{~m}^{-/-}$animals. In contrast, for antigen-experienced CD8 ${ }^{+}$ $\mathrm{T}$ cells, HSC-driven expansion did not require MHC class I expression on host cells. Key regulators of peripheral $\mathrm{T}$ cell homeostasis are homeostatic cytokines, especially IL-7 (13, 14, 50-52) and IL-15 $(13,53,54)$. While IL-15 mainly regulates memory T cell homeostasis, IL-7 is required for the homeostatic expansion of naive and memory T cells. We found elevated serum levels of both IL-7 and IL-15 after HSC transplantation in the myeloablative setting. The elevation was only transient - the peak occurred on day 5 after the HSC transplant - and corresponded with the observed expansion of transferred $\mathrm{T}$ cells as well as surviving endogenous host cells, perhaps indicating that these cells were consuming the homeostatic cytokines. The exact origin and induction of these cytokines after the HSC transplant requires further investigation.

Hematopoiesis has been closely investigated in the field of HSC transplantation (55) and could provide insight into the mechanism of HSC support of adoptively transferred T cells. Bone marrow-derived lin ${ }^{-}$cells prolong the survival of myeloablated animals via soluble factors (56). HSC support is not limited to $\mathrm{T}$ cells but is open to a variety of different cell types, such as NK cells, B cells, and monocytes. To influence several different cell types, HSCs could provide multiple factors or a single pluripotent factor that can impact a variety of cell types. One well-studied factor is IGF-1, which has been reported to enhance hematopoiesis, thymopoiesis, as well as T cell and B cell function (57). The IGF-1 receptor is found on thymocytes, T cells, B cells, and NK cells. IGF-1 can be released by HSCs and bone marrow stromal cells (58) and has been shown to increase the function of peripheral T cells, B cells, NK cells, and macrophages. IGF-1 may also have an antiapoptotic effect on peripheral T cells $(59,60)$, which perhaps explains the survival of endogenous lymphocytes that have received a damaging insult from TBI or chemotherapy. Other growth factors and cytokines have been reported to provide radioprotection when administered either before or shortly after the radiation exposure (56). For example, the administration of stem cell factor (SCF), Flt-3 ligand, TPO, IL-3, and SDF-1 together significantly prolonged the survival of myeloablated mice $(61,62)$. Radioprotection by these factors is probably mediated through an antiapoptotic effect on hematopoietic progenitor cells. Recently it has been shown that bone marrow lin $^{-}$cells can release soluble factors that prolong the survival of myeloablated animals (56). These factors seem to protect endogenous hematopoietic stem cells and possibly other surviving host cells. We have shown in this study that HSCs can augment the reconstitution of the lymphoid compartment not via progeny cells, but by increasing the expansion of host cells that survived and, importantly, of adoptively 
transferred $\mathrm{T}$ cells capable of destroying large tumor burdens in the absence of cancer vaccines. The finding that myeloablative lymphodepletion enabled HSCs to drive the expansion and function of adoptively transferred $\mathrm{CD}^{+} \mathrm{T}$ cells in the absence of competing host cells can have substantial implications for the design of new antitumor immunotherapies.

\section{Methods}

Mice and tumor lines. All mice used in these experiments were bred and housed at NIH facilities. Female pmel-1 TCR-Tg mice were crossed with C57BL/6-Thy $1.1^{+}-\mathrm{Tg}$ or C57BL/6-Ly5.1+-Tg mice (The Jackson Laboratory) to derive pmel-1-Thy $1.1^{+}$or pmel-1-Ly5.1+ double-Tg mice (C57BL/6pmel-1-Thy1.1+ mice are now available at http://www.jax.org). Female C57BL/6, $\mathrm{RAG}^{-/}, \mathrm{CD} 4{ }^{-/}, \mathrm{CD} 8^{-/-}$(The Jackson Laboratory), and $\beta_{2} \mathrm{~m}^{-/-}$ mice (Taconic) were used as recipients in ACT experiments. Experiments were conducted with the approval of the National Cancer Institute Animal Use and Care Committee. B16-F10 (H-2 $\left.2^{\mathrm{b}}\right)$, a spontaneous, transplantable gp $100^{+}$murine melanoma, was maintained in culture medium (CM).

In vitro activation of pmel- $1 \mathrm{CD} 8^{+} T$ cells. Pmel-1 splenocytes were isolated as described previously (23) and cultured in the presence of $1 \mu \mathrm{M}$ hgp $100_{25-33}$ and $\mathrm{CM}$ containing $30 \mathrm{IU} / \mathrm{ml}$ of rhIL-2 (Chiron). Cells were used for adoptive transfer 6-7 days after the start of the culture.

Adoptive transfers. Mice 6-12 weeks of age ( $n=5-6$ for all groups) were injected subcutaneously with $2 \times 10^{5}$ to $5 \times 10^{5}$ B16-F10 melanoma cells and treated 10-14 days later with intravenous adoptive transfer of in vitro-activated pmel-1 CD8 ${ }^{+} \mathrm{T}$ splenocytes. Lymphopenia was induced by nonmyeloablative ( $5 \mathrm{~Gy}$ ) or myeloablative ( $9 \mathrm{~Gy}$ ) TBI of tumor-bearing mice on the day of HSC transfer, which was 1 day prior to pmel- $1 \mathrm{CD} 8^{+} \mathrm{T}$ cell transfer. HSCs were extracted from the bone marrow by lineage depletion with streptavidin-coated magnetic beads (Dynabeads M-280 Streptavidin; Dynal Biotech) against biotin-labeled antibodies ( $\gamma \delta \mathrm{T}$ cell receptor, $\alpha \beta \mathrm{T}$ cell receptor, CD4, CD8a, NK1.1, Gr-1, B220, Ter-119, CD2, CD11b) (BD Biosciences) followed by a c-kit enrichment with CD117 MicroBeads (Miltenyi Biotec) and cultured for 18 hours in 10\% DMEM with 50 ng recombinant mouse IL-3 (rmIL-3), $500 \mathrm{ng}$ rmIL-6, and $500 \mathrm{ng}$ rmSCF (PeproTech); $1 \times 10^{5}$ cells were administered the following day directly after the irradiation. NK cells were depleted by intraperitoneal administration of $100 \mu \mathrm{g} /$ mouse of NA/LE antiNK1.1 antibody (BD Biosciences) every 5 days for a total of 5 doses. NA/LE anti- $\operatorname{Ig}_{2 \mathrm{a}} \mathrm{K}(100 \mu \mathrm{g} /$ mouse) was used as control antibody (BD Biosciences). Mice were vaccinated with $2 \times 10^{7} \mathrm{PFU}$ of a previously described (23) recombinant fowlpox virus expressing human gp100 (rFPhgp100; Therion Biologics). rhIL-2 (108 $\mu \mathrm{g} /$ dose; Chiron) was administered by intraperitoneal injection twice daily for a total of 6 doses. Tumors were measured using calipers, and the products of the perpendicular diameters were recorded. All experiments were performed in a blinded, randomized fashion and performed independently at least twice, with similar results.

Enumeration of cells in vivo and assessment of cytokine serum levels. At indicated time points, spleens were resected, and adoptively transferred CD8 ${ }^{+}$Thy $1.1^{+}$ or CD8 ${ }^{+} \mathrm{Ly} 5.1^{+}$pmel-1 CD8 ${ }^{+} \mathrm{T}$ cells were enumerated as previously described (23). Samples were analyzed by flow cytometry for B220, Gr1, CD8a, CD4, NK1.1, and Foxp3 expression (BD Biosciences). Cell numbers were calculated by multiplying the total number of live cells by the percentage of $\mathrm{B}_{220^{+}}, \mathrm{Gr}^{+}, \mathrm{CD} \mathrm{a}^{+}, \mathrm{CD}^{+} \mathrm{T}, \mathrm{Foxp}^{+}, \mathrm{CD}^{+}$, or NK1.1 $1^{+}$cells. Serum was collected from the tail vein at day 5 after HSC transplantation and assayed by murine LINCOplex cytokine assay (Linco Research).

Statistics. Tumor graphs were compared using ANOVA. $P$ values less than 0.05 were considered significant.

\section{Acknowledgments}

This research was supported by the Intramural Research Program of the NIH, National Cancer Institute, Center for Cancer Research. The authors would like to thank A. Mixon and S. Farid of the Flow Cytometry Unit (Surgery Branch of the NCI) for flow cytometry analyses; D. Jones for excellent technical support; and L. Cassard, B. Heemskerk, and D.J. Powell Jr. for critical review of the manuscript.

Received for publication September 21, 2006, and accepted in revised form November 21, 2006.

Address correspondence to: Claudia Wrzesinski or Nicholas P. Restifo, National Cancer Institute, National Institutes of Health, Bethesda, Maryland 20892, USA. Phone: (301) 451-6948; Fax: (301) 496-0011; E-mail: wrzesinc@mail.nih.gov (C. Wrzesinski). Phone: (301) 496-4904; Fax: (301) 496-0011; E-mail: restifo@ nih.gov (N.P. Restifo).
1. Gattinoni, L., Powell, D.J., Jr., Rosenberg, S.A., and Restifo, N.P. 2006. Adoptive immunotherapy for cancer: building on success. Nat. Rev. Immunol. 6:383-393.

2. Foster, A.E., and Rooney, C.M. 2006. Improving $\mathrm{T}$ cell therapy for cancer. Expert Opin. Biol. Ther. 6:215-229.

3. Yee, C., et al. 2002. Adoptive T cell therapy using antigen-specific CD8 $+\mathrm{T}$ cell clones for the treatment of patients with metastatic melanoma: in vivo persistence, migration, and antitumor effect of transferred T cells. Proc. Natl. Acad. Sci. U. S. A. 99:16168-16173.

4. Rosenberg, S.A., Yang, J.C., and Restifo, N.P. 2004. Cancer immunotherapy: moving beyond current vaccines. Nat. Med. 10:909-915.

5. Klebanoff, C.A., Gattinoni, L., and Restifo, N.P. 2006. CD8+ T-cell memory in tumor immunology and immunotherapy. Immunol. Rev. 211:214-224.

6. Overwijk, W.W., et al. 2003. Tumor regression and autoimmunity after reversal of a functionally tolerant state of self-reactive CD8+ T cells. J. Exp. Med. 198:569-580.

7. Cheever, M.A., Greenberg, P.D., and Fefer, A. 1980. Specificity of adoptive chemoimmunotherapy of established syngeneic tumors. J. Immunol. 125:711-714.
8. North, R.J. 1982. Cyclophosphamide-facilitated adoptive immunotherapy of an established tumor depends on elimination of tumor-induced suppressor T cells. J. Exp. Med. 155:1063-1074.

9. Gattinoni, L., et al. 2005. Removal of homeostatic cytokine sinks by lymphodepletion enhances the efficacy of adoptively transferred tumor-specific CD8+ T cells. J. Exp. Med. 202:907-912.

10. Maine, G.N., and Mule, J.J. 2002. Making room for T cells. J. Clin. Invest. 110:157-159. doi:10.1172/ JCI200216166.

11. Dudley, M.E., et al. 2005. Adoptive cell transfer therapy following non-myeloablative but lymphodepleting chemotherapy for the treatment of patients with refractory metastatic melanoma. J. Clin. Oncol. 23:2346-2357.

12. Dudley, M.E., et al. 2002. Cancer regression and autoimmunity in patients after clonal repopulation with antitumor lymphocytes. Science. 298:850-854

13. Goldrath, A.W., et al. 2002. Cytokine requirements for acute and basal homeostatic proliferation of naive and memory CD8+ T cells. J. Exp. Med. 195:1515-1522.

14. Schluns, K.S., and Lefrancois, L. 2003. Cytokine control of memory T-cell development and survival. Nat. Rev. Immunol. 3:269-279.
15. Cho, B.K., Rao, V.P., Ge, Q., Eisen, H.N., and Chen, J. 2000. Homeostasis-stimulated proliferation drives naive $\mathrm{T}$ cells to differentiate directly into memory T cells. J. Exp. Med. 192:549-556.

16. Kieper, W.C., and Jameson, S.C. 1999. Homeostatic expansion and phenotypic conversion of naive $\mathrm{T}$ cells in response to self peptide/MHC ligands. Proc. Natl. Acad. Sci. U. S. A. 96:13306-13311.

17. Antony, P.A., et al. 2005. CD8+ T cell immunity against a tumor/self-antigen is augmented by CD4+ $\mathrm{T}$ helper cells and hindered by naturally occurring $\mathrm{T}$ regulatory cells. J. Immunol. 174:2591-2601.

18. Turk, M.J., et al. 2004. Concomitant tumor immunity to a poorly immunogenic melanoma is prevented by regulatory T cells. J. Exp. Med. 200:771-782.

19. Viret, C., Wong, F.S., and Janeway, C.A., Jr. 1999. Designing and maintaining the mature TCR repertoire: the continuum of self-peptide: self-MHC complex recognition. Immunity. 10:559-568.

20. Goldrath, A.W., and Bevan, M.J. 1999. Low-affinity ligands for the TCR drive proliferation of mature CD8+ T cells in lymphopenic hosts. Immunity. 11:183-190.

21. Morgan, R.A., et al. 2006. Cancer regression in patients after transfer of genetically engineered 
lymphocytes. Science. 314:126-129.

22. Gattinoni, L., et al. 2005. Acquisition of full effector function in vitro paradoxically impairs the in vivo antitumor efficacy of adoptively transferred CD8+ T cells. J. Clin. Invest. 115:1616-1626. doi:10.1172/ JCI24480.

23. Palmer, D.C., et al. 2004. Vaccine-stimulated, adoptively transferred CD8 $+\mathrm{T}$ cells traffic indiscriminately and ubiquitously while mediating specific tumor destruction. J. Immunol. 173:7209-7216.

24. Zijlstra, M., et al. 1990. Beta 2-microglobulin deficient mice lack CD4-8+ cytolytic T cells. Nature. 344:742-746.

25. Kondo, M., et al. 2003. Biology of hematopoietic stem cells and progenitors: implications for clinical application. Annu. Rev. Immunol. 21:759-806.

26. Shen, S., et al. 2005. Control of homeostatic proliferation by regulatory T cells. J. Clin. Invest. 115:3517-3526. doi:10.1172/JCI25463.

27. Antony, P.A., et al. 2006. Interleukin-2-dependent mechanisms of tolerance and immunity in vivo. J. Immunol. 176:5255-5266.

28. Prlic, M., Blazar, B.R., Farrar, M.A., and Jameson, S.C. 2003. In vivo survival and homeostatic proliferation of natural killer cells. J. Exp. Med. 197:967-976.

29. Klebanoff, C.A., et al. 2004. IL-15 enhances the in vivo antitumor activity of tumor-reactive CD8+ T cells. Proc. Natl. Acad. Sci. U. S. A. 101:1969-1974.

30. Koka, R., et al. 2003. Interleukin (IL)-15Ralphadeficient natural killer cells survive in normal but not IL-15Ralpha-deficient mice. J. Exp. Med. 197:977-984.

31. Quezada, S.A., Peggs, K.S., Curran, M.A., and Allison, J.P. 2006. CTLA4 blockade and GM-CSF combination immunotherapy alters the intratumor balance of effector and regulatory T cells. J. Clin. Invest. 116:1935-1945. doi:10.1172/JCI27745.

32. Sato, E., et al. 2005. Intraepithelial CD8+ tumorinfiltrating lymphocytes and a high $\mathrm{CD} 8+/$ regulatory $\mathrm{T}$ cell ratio are associated with favorable prognosis in ovarian cancer. Proc. Natl. Acad. Sci. U. S. A. 102:18538-18543.

33. Zhang, L., et al. 2003. Intratumoral T cells, recurrence, and survival in epithelial ovarian cancer. N. Engl. J. Med. 348:203-213.

34. Bronte, V., et al. 1998. Apoptotic death of CD8+ $\mathrm{T}$ lymphocytes after immunization: induction of a suppressive population of Mac-1+/Gr-1+ cells. J. Immunol. 161:5313-5320.

35. Gallina, G., et al. 2006. Tumors induce a subset of inflammatory monocytes with immunosuppressive activity on $\mathrm{CD}^{+} \mathrm{T}$ cells. J. Clin. Invest. 116:2777-2790. doi:10.1172/JCI28828.
36. Frey, A.B. 2006. Myeloid suppressor cells regulate the adaptive immune response to cancer. J. Clin. Invest. 116:2587-2590. doi:10.1172/JCI29906.

37. Garnett, C.T., et al. 2004. Sublethal irradiation of human tumor cells modulates phenotype resulting in enhanced killing by cytotoxic T lymphocytes. Cancer Res. 64:7985-7994.

38. Reits, E.A., et al. 2006. Radiation modulates the peptide repertoire, enhances MHC class I expression, and induces successful antitumor immunotherapy. J. Exp. Med. 203:1259-1271.

39. Muranski, P., et al. 2006. Increased intensity lymphodepletion and adoptive immunotherapy - how far can we go? Nat. Clin. Pract. Oncol. 3:668-681.

40. Walter, E.A., et al. 1995. Reconstitution of cellular immunity against cytomegalovirus in recipients of allogeneic bone marrow by transfer of T-cell clones from the donor. N. Engl. J. Med. 333:1038-1044.

41. Papadopoulos, E.B., et al. 1994. Infusions of donor leukocytes to treat Epstein-Barr virus-associated lymphoproliferative disorders after allogeneic bone marrow transplantation. N. Engl. J. Med. 330:1185-1191.

42. Haque, T., et al. 1998. Reconstitution of EBV-specific $\mathrm{T}$ cell immunity in solid organ transplant recipients. J. Immunol. 160:6204-6209.

43. Haque, T., et al. 2002. Treatment of Epstein-Barrvirus-positive post-transplantation lymphoproliferative disease with partly HLA-matched allogeneic cytotoxic T cells. Lancet. 360:436-442.

44. Rooney, C.M., et al. 1998. Infusion of cytotoxic T cells for the prevention and treatment of EpsteinBarr virus-induced lymphoma in allogeneic transplant recipients. Blood. 92:1549-1555.

45. Riddell, S.R., et al. 1992. Restoration of viral immunity in immunodeficient humans by the adoptive transfer of T cell clones. Science. 257:238-241.

46. Heslop, H.E., et al. 1996. Long-term restoration of immunity against Epstein-Barr virus infection by adoptive transfer of gene-modified virus-specific $\mathrm{T}$ lymphocytes. Nat. Med. 2:551-555.

47. Porrata, L.F., et al. 2001. Early lymphocyte recovery predicts superior survival after autologous hematopoietic stem cell transplantation in multiple myeloma or non-Hodgkin lymphoma. Blood. 98:579-585.

48. Rapoport, A.P., et al. 2005. Restoration of immunity in lymphopenic individuals with cancer by vaccination and adoptive T-cell transfer. Nat. Med. 11:1230-1237.

49. Barlogie, B., et al. 2004. Treatment of multiple myeloma. Blood. 103:20-32.

50. Tan, J.T., et al. 2001. IL-7 is critical for homeostatic proliferation and survival of naive T cells. Proc. Natl.
Acad. Sci. U. S. A. 98:8732-8737.

51. Schluns, K.S., Kieper, W.C., Jameson, S.C., and Lefrancois, L. 2000. Interleukin-7 mediates the homeostasis of naive and memory CD8 T cells in vivo. Nat. Immunol. 1:426-432.

52. Fry, T.J., and Mackall, C.L. 2005. The many faces of IL-7: from lymphopoiesis to peripheral T cell maintenance. J. Immunol. 174:6571-6576.

53. Tan, J.T., et al. 2002. Interleukin (IL)-15 and IL-7 jointly regulate homeostatic proliferation of memory phenotype CD8+ cells but are not required for memory phenotype CD4+ cells. J. Exp. Med. 195:1523-1532.

54. Alves, N.L., Hooibrink, B., Arosa, F.A., and van Lier, R.A. 2003. IL-15 induces antigen-independent expansion and differentiation of human naive CD8+ T cells in vitro. Blood. 102:2541-2546.

55. van den Brink, M.R., Alpdogan, O., and Boyd, R.L. 2004. Strategies to enhance T-cell reconstitution in immunocompromised patients. Nat. Rev. Immunol. 4:856-867.

56. Zhao, Y., Zhan, Y., Burke, K.A., and Anderson, W.F. 2005. Soluble factor(s) from bone marrow cells can rescue lethally irradiated mice by protecting endogenous hematopoietic stem cells. Exp. Hematol. 33:428-434.

57. Clark, R., Strasser, J., McCabe, S., Robbins, K., and Jardieu, P. 1993. Insulin-like growth factor-1 stimulation of lymphopoiesis. J. Clin. Invest. 92:540-548.

58. Stuart, C.A., Meehan, R.T., Neale, L.S., Cintron, N.M., and Furlanetto, R.W. 1991. Insulin-like growth factor-I binds selectively to human peripheral blood monocytes and B-lymphocytes. J. Clin. Endocrinol. Metab. 72:1117-1122.

59. Welniak, L.A., Sun, R., and Murphy, W.J. 2002. The role of growth hormone in T-cell development and reconstitution. J. Leukoc. Biol. 71:381-387.

60. Dobashi, H., Sato, M., Tanaka, T., Tokuda, M., and Ishida, T. 2001. Growth hormone restores glucocorticoid-induced $\mathrm{T}$ cell suppression. FASEB J. 15:1861-1863.

61. Drouet, M., et al. 2004. Single administration of stem cell factor, FLT-3 ligand, megakaryocyte growth and development factor, and interleukin3 in combination soon after irradiation prevents nonhuman primates from myelosuppression: long-term follow-up of hematopoiesis. Blood. 103:878-885

62. Herodin, F., Bourin, P., Mayol, J.F., Lataillade, J.J., and Drouet, M. 2003. Short-term injection of antiapoptotic cytokine combinations soon after lethal gamma-irradiation promotes survival. Blood. 101:2609-2616. 